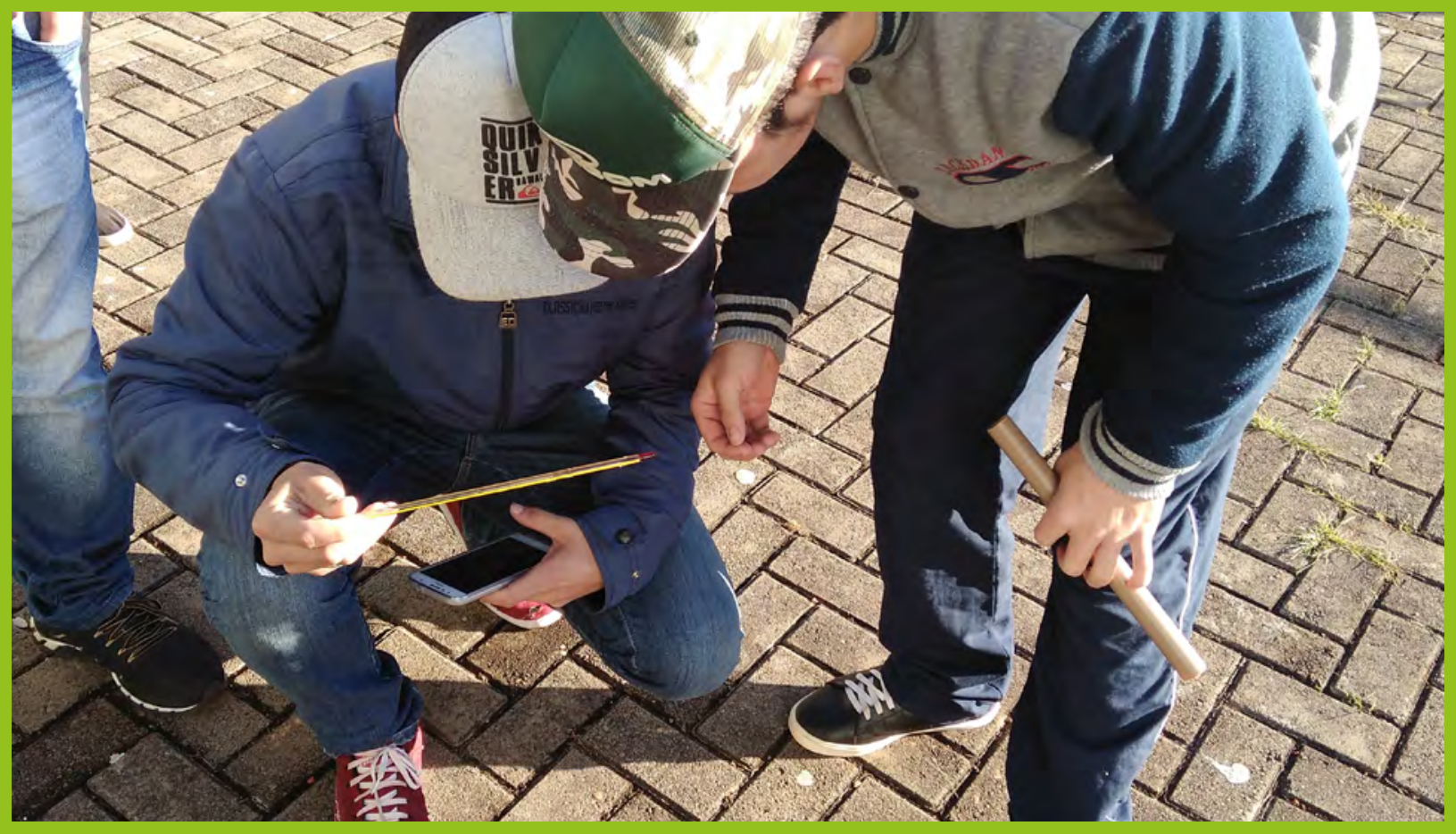

\title{
Estimando a temperatura da superfície do Sol: um experimento, três enfoques
}

Renato da Silva Rosa Rodrigues ${ }^{1}$

renato.rodrigues@ifsc.edu.br

Jairo Gonçalves Carlos ${ }^{2}$

jairo.carlos@ifsc.edu.br 
Neste trabalho apresentam-se os resultados de um projeto de extensão e pesquisa constituído por um conjunto de atividades práticas de caráter experimental, desenvolvidas com estudantes dos três anos do ensino médio, cujo objetivo era estimar a temperatura da superfície do Sol. Durante a pesquisa, foram utilizados como instrumentos de coleta de dados diversos questionários, entrevista semiestruturada e registro das atividades de campo. 0 pressuposto teórico-metodológico básico foi o ensino por investigação. Os resultados obtidos evidenciaram a necessidade de se promover ações mais sistemáticas que possibilitem a exposição dos estudantes a uma gama maior de experiências, concepções e reflexões sobre a ciência, seus conceitos e dimensões históricas, filosóficas e sociológicas.

Palavras-Chave: Experimentação. Ensino por Investigação. Ensino de Física. Natureza da Ciência.

ABSTRACT

In this work are presented the results of an extension/research project constituted by a set of practical and experimental activities developed with high school students. The goal was to estimate the sun's surface temperature. During this research, techniques of data collect like questionnaires, semi-structured interview and field research annotations were applied, according to inquiry based learning. The results obtained suggest the need of promoting more systematic actions which provide a more intense contact of the students with experiences, conceptions and reflections about science as its concepts and historical, philosophical and sociological dimensions.

Keywords: Experimentation. Inquiry Based Learning. Physics Education. Nature of Science.

\section{INTRODUÇÃO}

Desde o século XVII, a experimentação cresceu como elemento constitutivo da prática e da tradição científica, estando presente ao longo de todo o processo de desenvolvimento dos saberes e competências em Física e em outras áreas do conhecimento, privilegiando-se o fazer, manusear, operar e agir, em diferentes formas e níveis. Dessa maneira, a experimentação tornou-se parte da própria natureza do conhecimento científico, sendo, portanto, elemento indispensável para facilitar a (re)construção do conhecimento pelo próprio aluno, desenvolvendo sua curiosidade e o hábito de indagar, evitando a aquisição do conhecimento científico como uma verdade estabelecida e inquestionável (BRASIL, 2002).

Diante do exposto, torna-se necessário implementar atividades práticas e experimentais no ensino de Física. No entanto, boa parte das escolas, sobretudo as públicas, não dispõem de um laboratório para execução desse tipo de atividade (SOARES NETO et al., 2013). Nesses casos, a execução de atividades experimentais commateriais de baixo custo torna-se uma alternativa relevante ao ensino de Física, envolvendo os estudantes com a construção de aparatos e promovendo o gosto pelo fazer científico e pedagógico.

Nesse trabalho apresentam-se os resultados da aplicação de uma atividade prática e experimental no contexto de um projeto de extensão/pesquisa do Instituto Federal de Santa Catarina, Câmpus Xanxerê, em turmas de ensino médio de uma escola pública estadual da cidade. Trata-se de uma montagem experimental de baixo custo e fácil acesso, utilizada para estimar a temperatura da superfície do Sol. A proposta experimental compõe um produto instrucional desenvolvido no contexto do Mestrado Nacional Profissional em Ensino de Física (RODRIGUES, 2016), e planejada para ser desenvolvida com estudantes do segundo ano do ensino médio. Todavia, neste projeto de extensão e pesquisa, ela foi desenvolvida nos três anos com enfoques distintos.

Dentre as diversas abordagens possíveis, optou-se por desenvolver as atividades práticas e experimentais de acordo com a perspectiva teórico-metodológica do ensino por investigação (SASSERON, 2015), segundo a qual

[...] o ensino por investigação extravasa o âmbito de uma metodologia de ensino apropriada apenas a certos conteúdos e temas, podendo ser colocada em prática nas mais distintas aulas, sob as mais diversas formas e para os diferentes conteúdos. Denota a intenção do professor em possibilitar o papel ativo de seu aluno na construção de entendimento sobre os conhecimentos científicos. Por esse motivo, caracteriza-se por ser uma forma de trabalho que o professor utiliza na intenção de fazer com que a turma se engaje com as discussões e, ao mesmo tempo em que travam contato com fenômenos naturais, pela busca de resolução de um problema, exercitam práticas e raciocínios de comparação, análise e avaliação bastante utilizadas na prática científica (SASSERON, 2015, p. 58). 
Nesse sentido, durante a implementação do projeto, buscou-se criar situações que favorecessem o protagonismo do estudante mediante um engajamento reflexivo, discursivo e argumentativo, numa perspectiva investigativa e colaborativa com diferentes enfoques para cada série. Ou seja, procurou-seaplicar a mesma atividade experimental sob perspectivas diferentes, de acordo com os objetivos educacionais e conceitos físicos pertinentes a cada etapa.

Ao definir a abordagem a ser adotada no 1 ㅇano do ensino médio, considerou-se que os alunos estavam se familiarizando com a disciplina, suas características, métodos e objeto de estudo. Portanto jugou-se apropriado apresentar a Física como uma ciência de caráter experimental, resultado de um construto humano, buscando evitar uma possível visão deturpada da mesma como uma disciplina repleta de fórmulas matemáticas utilizadas meramente para a resolução de exercícios. Nesse caso, a abordagem escolhida teve como referência aspectos relativos à natureza da ciência.

A natureza da Ciência é entendida como um conjunto de elementos que tratam da construção, estabelecimento e organização do conhecimento científico. Isto pode abranger desde questões internas, tais como método científico e relação entre experimento e teoria, até outras externas, como a influência de elementos sociais, culturais, religiosos e políticos na aceitação ou rejeição de ideias científicas (MOURA, 2014, p. 32).

- A ideia defendida pelo autor e assumida neste projeto é de que, mais do que ensinar conceitos científicos, é imperativo ensinar também sobre a ciência, sendo esta um elemento fundamental para a formação crítica e integrada com o mundo real.

- Moura (2014) apresenta cinco elementos consensuais que compõem o escopo da Natureza da Ciência. Tais elementos foram adotados como parâmetros para a abordagem da atividade experimental realizada com os estudantes do 1 음 ano. São eles:

- A Ciência é mutável, dinâmica e tem como objetivo buscar explicar os fenômenos naturais.

- Não existe um método científico universal.

- A teoria não é consequência da observação/experimento e vice-versa.

- A Ciência é influenciada pelo contexto social, cultural, político etc., no qual ela é construída.

- Os cientistas utilizam imaginação, crenças pessoais, influências externas, entre outros para fazer Ciência.

A mesma atividade experimental foi desenvolvida com os estudantes do 20 ano, porém o foco foi conceitual, haja vista a afinidade do experimento com os conceitos físicos ensinados nessa etapa do ensino médio. Nesse caso, abordaram-se os conceitos de calor, temperatura e energia interna, que muitas vezes são mal compreendidos pelos estudantes e até mesmo por professores. A fundamentação teórica para tal abordagem proveio da pesquisa realizada por Silva, Laburú e Nardi (2008) na qual os autores discorrem sobre o conceito de calor, destacando sua complexidade, suas variações e suas nuances, procurando definir as situações, condições de validade e aplicabilidade deste conceito, bem como demarcar sua distinção em relação a conceitos correlatos como temperatura e energia interna.

De acordo com Silva, Laburú e Nardi (2008, p. 389):

[...] um corpo não tem calor, tem energia; mas quando se transfere parte dessa energia numa situação de diferença de temperatura, refere-se a ela como a quantidade de calor transferida, compreendendo-se, portanto, que o corpo teve um acréscimo de energia em forma de calor. Esse entendimento, além de não fazer referência ao calor em um corpo, satisfaz o uso da expressão quantidade de calor que tem desempenhado um papel tão importante em tantos livros didáticos e tabelas, sendo quase impossível de ser evitada.

Ou seja, afirmam que o "[...] calor, é antes, uma forma de transferir energia e não a energia [...]" (SILVA; LABURÚ; NARDI, 2008, p. 390, grifo dos autores). Essas e outras ideias, exemplos e orientações constituíram a base teórica de referência para a discussão sobre tais conceitos com os estudantes, antes e após a realização da atividade experimental.

Por fim, realizou-se o mesmo experimento com os estudantes do 3o ano do ensino médio. Contudo, nesse caso em particular, a discussão teve como foco os aspectos históricos relacionados ao surgimento da Física Quântica, a partir da discussão do problema da radiação de corpo negro. 
A elaboração do plano de ensino para a abordagem desse tema baseou-se na pesquisa e no produto instrucional desenvolvido por Rodrigues (2016) e no texto de apoio ao professor de Física desenvolvido por Griebeler e Moreira (2012).

\begin{abstract}
Inserir conteúdos de Física Quântica no Ensino Médio torna-se um desafio para os professores, tanto por uma possível falta de preparo como pela falta de incentivo. Apesar da existência de materiais didáticos disponíveis, raramente os professores sentem-se preparados para abordar tais conteúdos em sala de aula. Além disso, o atual currículo do Ensino Médio bem como o programa ENEM, não estimulam ao ensino do assunto aqui referido. No entanto, em função da importância da abordagem da Física Quântica, e também frente à propagação de versões místicas e de representações sociais, é preciso continuar tentando contribuir para que essa inserção venha a ocorrer futuramente (GRIEBELER; MOREIRA, 2012, p. 6).
\end{abstract}

Nesse sentido, considerou-se que a discussão sobre o contexto histórico e científico que culminou com o advento da Física Quântica poderia ampliar os horizontes da formação desses estudantes, abrindo novas possibilidades de estudo, leitura e aprofundamento de conceitos da Física moderna. Além disso, a teoria da radiação de corpo negro tem um papel estruturante no embasamento teórico da atividade experimental realizada, já que "a temperatura efetiva de uma estrela é definida como a temperatura de um corpo negro que emite a mesma quantidade de energia por unidade de área e por unidade de tempo que a estrela" (RODRIGUES, 2016, p. 63).

Após a discussão sobre o conceito de corpo negro e sua relação com o surgimento da física quântica, destacaram-se as implicações científicas, tecnológicas e filosóficas dessa revolução científica para o desenvolvimento da chamada 3a Revolução Industrial, com destaque para o desenvolvimento da microeletrônica, que está na vanguarda das telecomunicações e da microinformática, dentre outros.

\title{
2 METODOLOGIA
}

A atividade prática e experimental consistiu na estimativa da temperatura da superfície do Sol. Ela foi baseada em pressupostos teóricos como a equação fundamental da calorimetria, o conceito de luminosidade e a Lei de Stefan-Boltzmann. Com o intuito de simplificar a atividade e dar enfoque aos aspectos da natureza da ciência, nos conceitos de temperatura, calor e energia interna, bem como no problema da radiação de corpo negro, durante a atividade optou-se por não apresentar aos estudantes a dedução matemática da equação que estima a temperatura da superfície do Sol, em função dos parâmetros medidos na experiência. Dessa forma, apresentou-se a equação já na sua forma final. Para a realização da atividade foram utilizados os seguintes materiais:

Recipiente de isopor (bandeja retangular pequena) na cor original (branco) e na cor preta fosca, pintado à mão com tinta PVA à base de água;

- Termômetro;

- Cronômetro;

- Régua escolar;

- Bastão de madeira de aproximadamente $30 \mathrm{~cm}$.

De posse dos materiais, com o auxílio dos bolsistas do projeto (estudantes do curso Técnico Integrado em Mecânica) e organizados em grupos, os estudantes executaram os seguintes passos:

Preencheram os recipientes com água na temperatura ambiente;

- Mediram a altura da coluna de água no recipiente;

- Mediram a temperatura inicial da água;

- Colocaram os recipientes com água totalmente expostos ao Sol;

- Aguardaram por aproximadamente 5 minutos (Figura 1);

- Registraram o tempo aguardado;

- Mediram a nova temperatura (Figura 2);

- Seguraram o bastão de madeira perpendicularmente ao solo; 
- Mediram a altura do bastão a partir do solo;

- Mediram o comprimento da sombra do bastão perpendicular projetada no solo (Figura 3).

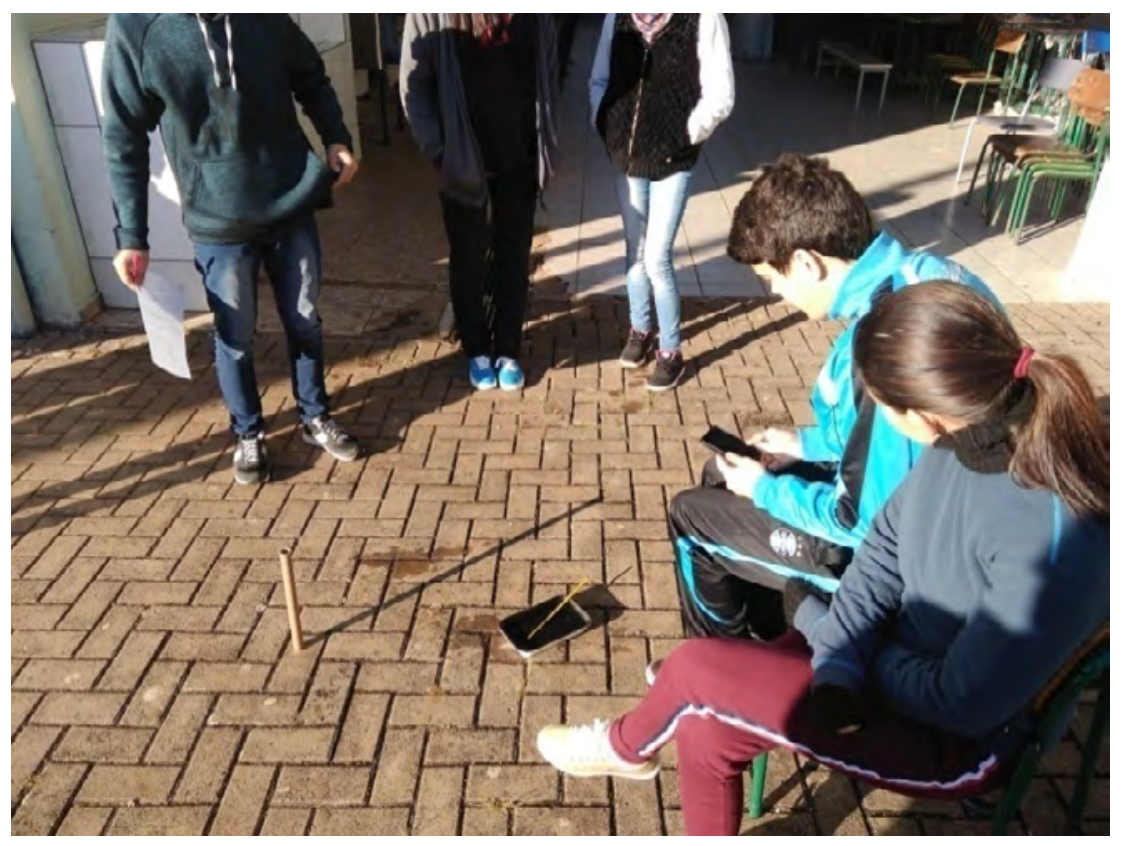

Figura 1: Estudantes aguardando o tempo necessário para a leitura da temperatura no termômetro. Fonte: Acervo do projeto.

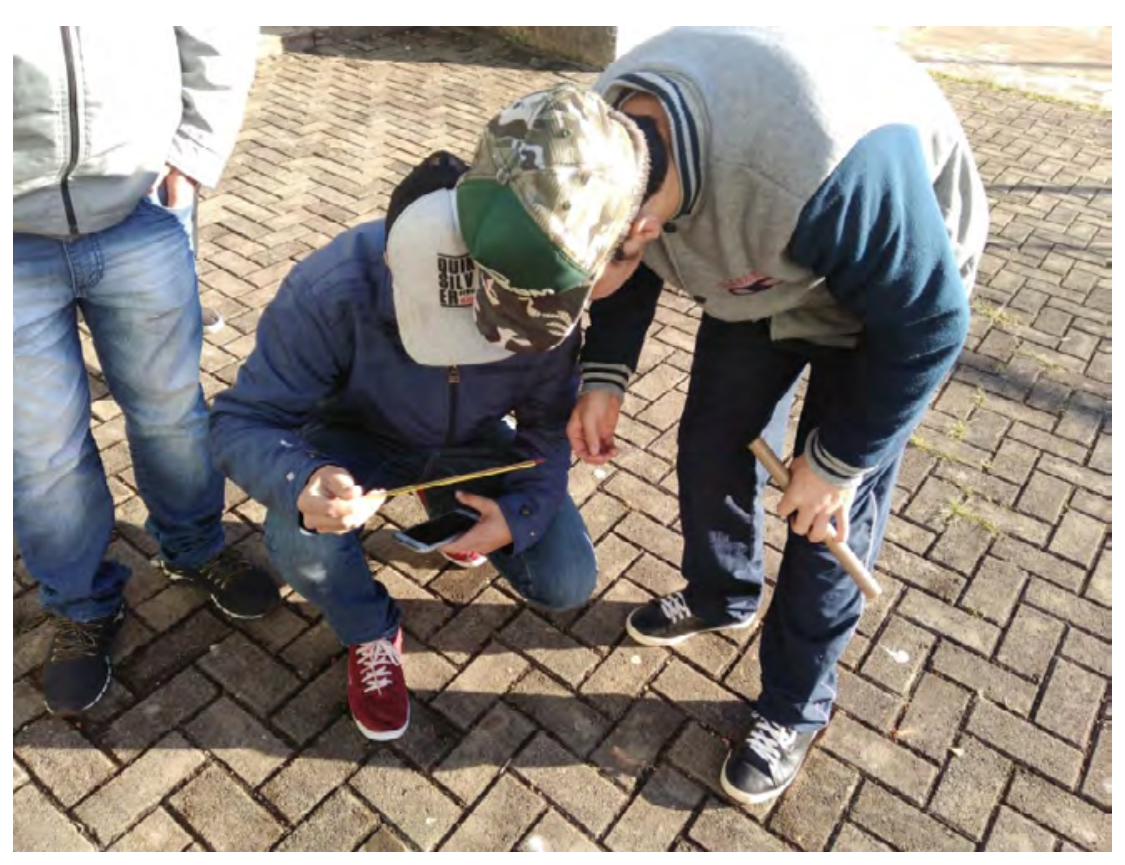

Figura 2: Estudantes fazendo a leitura da temperatura no termômetro. Fonte: Acervo do projeto.

De posse dos dados obtidos nas medições realizadas, seguiram um roteiro para a realização dos cálculos necessários para a obtenção da temperatura estimada da superfície do Sol com o uso de calculadoras e a orientação dos bolsistas, sob a supervisão da professora regente da turma e dos coordenadores do projeto. É importante ressaltar que os estudantes bolsistas realizaram a atividade experimental previamente e receberam instruções dos coordenadores para atuarem como tutores dos estudantes da escola participante. Nesse sentido, eles foram protagonistas na etapa de execução da atividade experimental, tendo a oportunidade de mediar e interagir com os demais estudantes. 


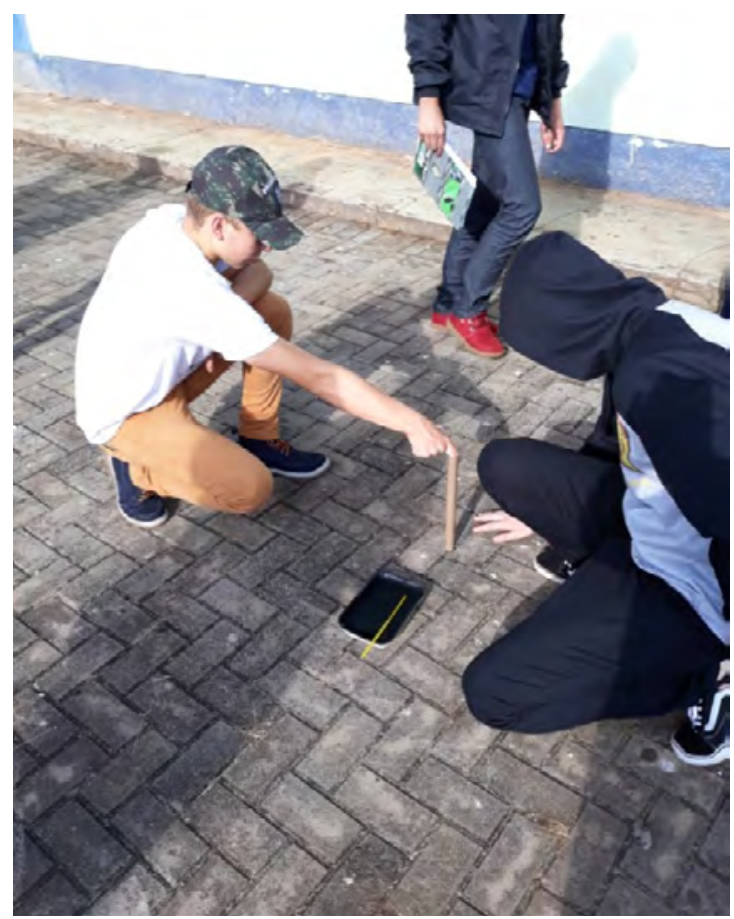

Figura 3: Estudantes medindo o comprimento da sombra projetada.

Fonte: Acervo do projeto.

Como se pode notar, a atividade experimental realizada configurou-se como uma atividade de caráter quantitativo e verificacionista (ARAÚJO; ABIB, 2003), na medida em que possibilitou aos estudantes comparar o resultado obtido com o resultado teórico fornecido, permitindo, assim, uma avaliação das teorias da Física envolvidas, do modelo matemático utilizado e dos métodos empíricos empregados. No entanto, de acordo com Araújo e Abib (2013), mesmo atividades experimentais com esse caráter, quando planejadas sob o escopo de uma metodologia de investigação construtiva, adquirem contornos que vão muito além da verificação de leis e métodos. Dessa forma, a problematização inicial dos fenômenos possibilitou uma discussão conceitual, que pôde em alguma medida ser direcionada para os elementos que se pretendiam enfatizar em cada turma. Além disso, o fomento desse tipo de discussão deu abertura para os estudantes refletirem sobre a prática e exporem suas concepções prévias.

A primeira etapa do projeto de extensão e pesquisa foi realizada com os estudantes do 10 ano. Inicialmente, fez-se uma problematização do fenômeno, da atividade experimental e um levantamento das concepções prévias dos estudantes, mediante a aplicação de um questionário para avaliar suas representações sobre a natureza da ciência (pré-teste). 0 questionário consistiu numa adaptação de um instrumento para avaliação das visões sobre a natureza da ciência proposto por Chen (2006). No segundo momento, os alunos realizaram a atividade experimental, com a assistência dos estudantes bolsistas e sob a supervisão e orientação do coordenador do projeto e da professora de Física da turma (colaboradora do projeto). No terceiro momento desta primeira etapa, retornou-se à sala de aula para compartilhar, analisar e discutir os resultados, à luz dos cinco pilares constitutivos da natureza da ciência (MOURA, 2014), que foram escolhidos para estruturar a atividade. Por fim, foi aplicado um questionário idêntico ao anterior (pós-teste) com questões de múltipla escolha que possibilitassem evidenciar a concepção dos estudantes sobre cada um dos cinco pilares da natureza da ciência, mencionados na introdução deste artigo.

A segunda etapa, por sua vez, foi realizada com os estudantes do 20 ano. Nesse caso, realizou-se a mesma atividade experimental, com foco conceitual. Nesse sentido, com o intuito de harmonizar e otimizar a contribuição da atividade para a aprendizagem dos estudantes, foi combinado com a professora de Física qual seria a melhor ocasião, de acordo com o seu planejamento e cronograma de conteúdos, para se realizar o experimento e a discussão conceitual com os estudantes.

A metodologia para a realização da atividade foi a mesma do 10 ano, consistindo de três momentos: problematização e aplicação do pré-teste; execução do procedimento experimental, com a assistência dos bolsistas; e socialização, análise e discussão dos resultados experimentais, seguidas da aplicação do pósteste. Embora o procedimento metodológico tenha se repetido, o mesmo não aconteceu com o foco teórico da atividade, que priorizou, tanto na problematização quanto na discussão dos resultados, os aspectos conceituais, com ênfase para os conceitos físicos de calor, temperatura e energia interna, que são objetos de aprendizagem relevantes para estudantes do 20 ano do ensino médio. Coerentemente com o processo, 0 
questionário (pré e pós-teste) consistiu de questões objetivas envolvendo esses três conceitos e a relação entre eles. Este questionário foi adaptado de um teste avaliativo das concepções científicas dos estudantes sobre calor, temperatura e energia interna desenvolvido por Lang da Silveira e Moreira (1996).

A terceira e última etapa do projeto foi realizada com os estudantes do 3 - ano. 0 principal objetivo foi utilizar a atividade experimental como ponto de partida para a discussão de aspectos conceituais e históricos inerentes ao nascimento da Física moderna, em particular, o problema da radiação de corpo negro. Para tanto, repetiu-se a metodologia utilizada nas etapas anteriores. Inicialmente, o procedimento experimental foi explicado e, durante esse processo discutiram-se os conceitos propostos. 0 segundo momento da atividade consistiu da realização da atividade experimental com a coleta de dados e obtenção do resultado. Após a realização do procedimento, fez-se uma discussão dos resultados, enfatizando a validade do modelo matemático, das teorias e dos conceitos empregados. Por fim, foi aplicada uma atividade em que os estudantes deveriam elaborar um texto dissertativo-argumentativo contendo algumas palavras-chave escolhidas dentre um conjunto de palavras previamente indicadas com o intuito de possibilitar, de alguma maneira, um feedback aos pesquisadores sobre como os estudantes assimilaram os conceitos discutidos e como estabeleceram a inter-relação entre eles.

Ao todo, participaram das atividades 142 estudantes, sendo que o tempo destinado para a realização da atividade em cada turma foi de 2 horas-aula, totalizando 12 horas-aula de atividades práticas com a participação dos bolsistas extensionistas na escola.

\section{RESULTADOS E DISCUSSÃO}

No que diz respeito aos resultados qualitativos, percebeu-se uma acentuada participação dos estudantes dos três anos do ensino médio na atividade experimental. Essa participação ocorreu tanto do ponto de vista de foco, atenção e interação, por meio de perguntas, relatos e comentários - como no momento da montagem do experimento, execução, coleta de dados e realização dos cálculos. Inclusive, nessa fase operacional, a atuação dos bolsistas voluntários foi fundamental, pois cada um(a) teve a oportunidade de participar da execução do experimento com um grupo de estudantes, auxiliando-os na realização do experimento e buscando a orientação dos professores, quando necessário.

Segundo relatos da professora regente da turma e colaboradora do projeto de extensão, a repercussão da atividade foi positiva para os estudantes do 10 ano, na medida em que contribuiu para uma melhor percepção do caráter processual do conhecimento científico e a evidenciação de algumas características da natureza da ciência, o que acabou por influenciar positivamente a concepção dos estudantes sobre a Física.

Já a análise dos dados dos questionários pré e pós-teste do 1 ํㅡo ano revelou indícios da preponderância da dimensão prática da atividade sobre a discussão teórica acerca da natureza da ciência. Ou seja, os aspectos da natureza da ciência diretamente ligados à atividade experimental tiveram maior impacto do que aqueles reforçados apenas no discurso dos professores. As implicações desta constatação apontam para a necessidade de se estender e diversificar os temas, abordagens e natureza das atividades experimentais no decorrer do ano letivo, com o intuito de abranger uma quantidade maior de elementos da prática científica e contribuir para uma visão mais representativa da complexidade da natureza da ciência.

A análise dos dados das turmas mostrou discrepância na qualidade entre os resultados obtidos com as duas turmas do mesmo nível. Nos três casos, as turmas 01 (1이, 01, 2은 01 e 3이) 01) demonstraram um desempenho/aproveitamento sensivelmente melhor da atividade do que as turmas 02 (1으 02, 2은 02 e 3 은 02). Tal fato suscitou a hipótese de que tais turmas tivessem perfis conceituais, comportamentais e de aprendizagem marcadamente distintos (MORTIMER, 1995).

Com o intuito de averiguar tal hipótese, realizou-se uma entrevista com a professora regente das turmas. Foi constatado que, do ponto de vista conceitual e social, as turmas não apresentam diferenças significativas e que o critério utilizado pela escola para a formação dos dois grupos foi a opção dos estudantes por cursar, como componente curricular de língua estrangeira, inglês ou espanhol. Embora o desempenho acadêmico não tenha sido fator decisivo para a formação das turmas, o depoimento da professora revelou que as mesmas apresentam diferenças significativas quanto ao envolvimento nos processos de ensino e aprendizagem, sendo que as turmas 01 tendem a manter maior grau de concentração e dedicação às atividades, enquanto as turmas 02 tendem a ser mais dispersas e displicentes.

Dessa forma, evidencia-se que a implementação de uma mesma estratégia de ensino para turmas com perfis distintos não produz níveis de aprendizagem similares, tornando-se necessário um planejamento que considere suas peculiaridades.

Coerentemente com os objetivos do projeto, o foco da atividade experimental com os estudantes do 1 -ano foi a discussão de elementos relacionados à natureza da ciência, portanto a atividade, assim como o questionário, tinham uma orientação explicitamente qualitativa, não sendo passível de análise quantitativa, nesse caso. 
Já o foco da atividade realizada com as turmas do $2^{\circ}$ ano, por sua vez, foram os conceitos de calor, temperatura e energia interna, conforme mencionado. Nesse caso, os questionários aplicados (pré e pósteste) pretendiam avaliar o nível de compreensão de tais conceitos por parte dos estudantes.

Os gráficos das figuras 4 e 5 apresentam um panorama dos resultados obtidos nessa atividade.

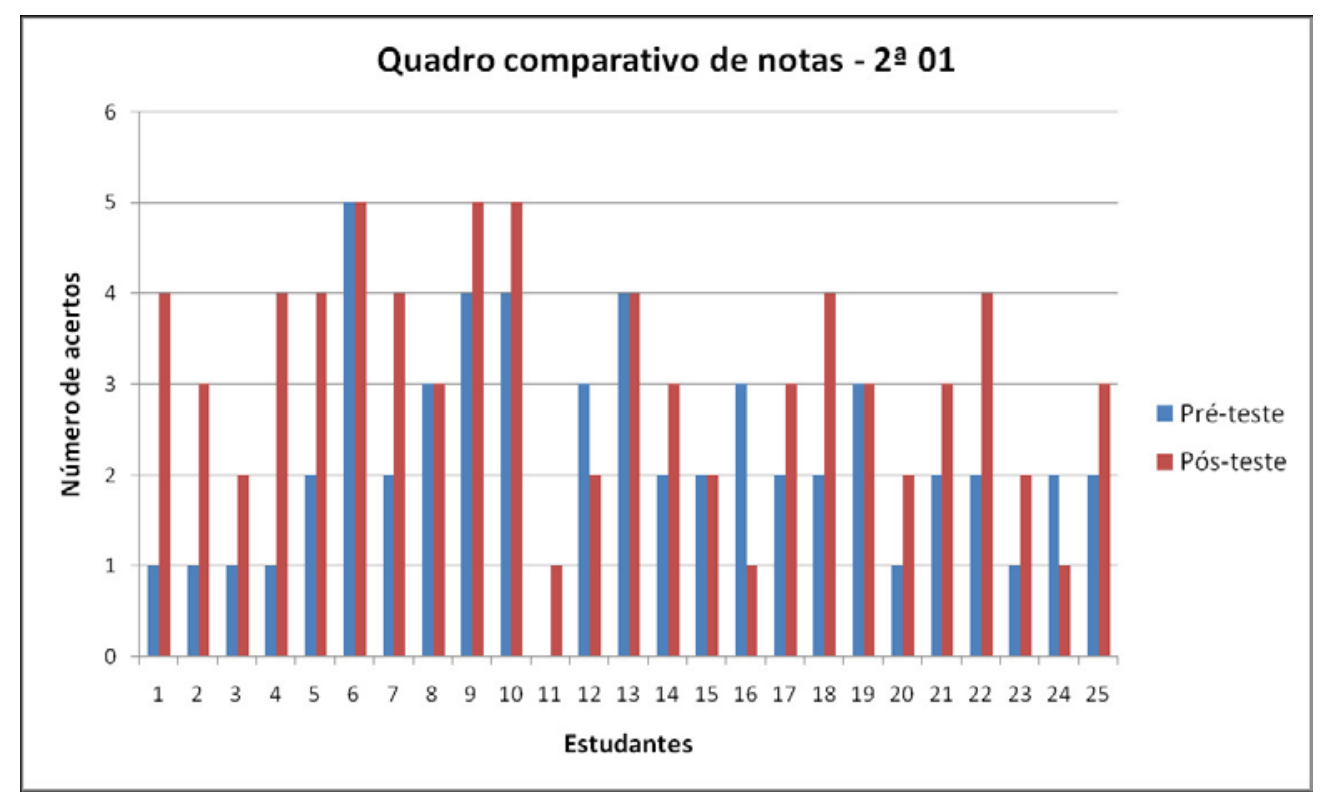

Figura 4: Comparativo entre o número de acertos das questões, antes e depois da realização da atividade na turma 2001 .

Fonte: Dados desta pesquisa.

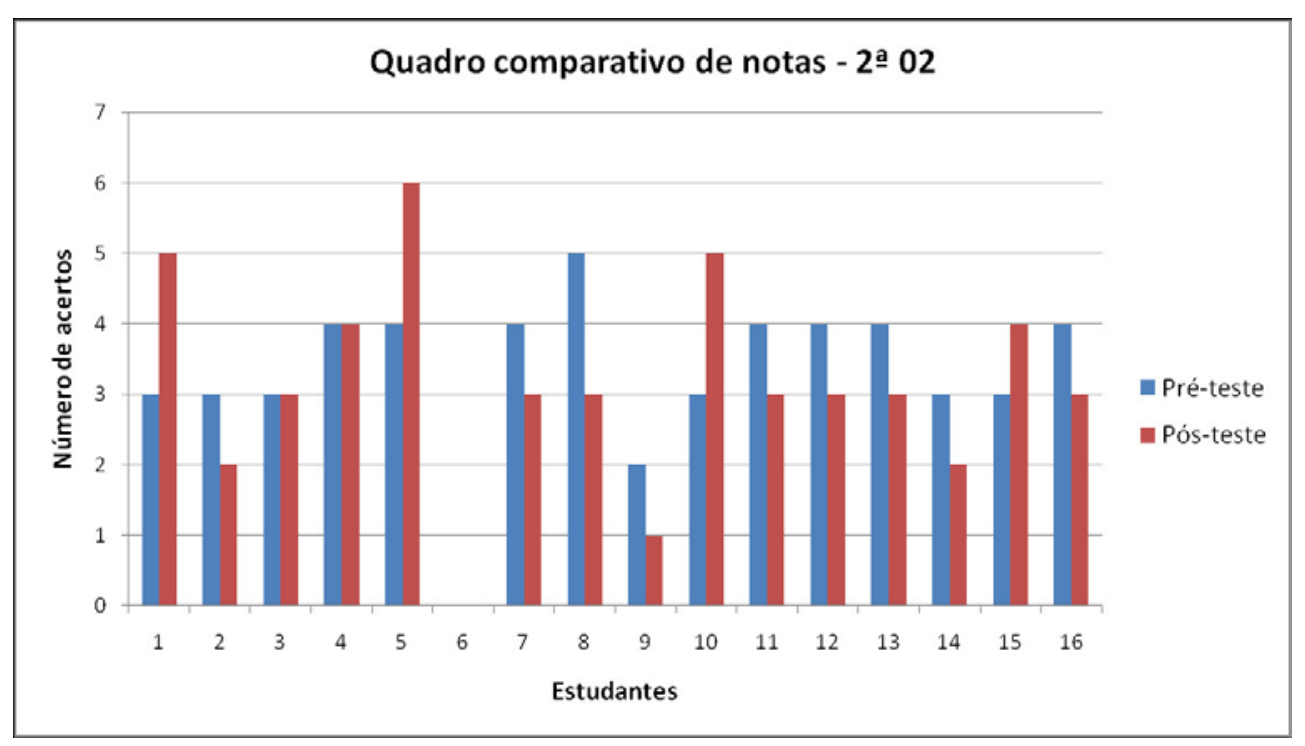

Figura 5: Comparativo entre o número de acertos das questões, antes e depois da realização da atividade na turma 2 응. 02 .

Fonte: Dados desta pesquisa.

Os gráficos das figuras 4 e 5 evidenciam a diferença de desempenho das turmas 01 e 02 . A melhoria no rendimento global da turma 01 foi de $40 \%$ entre o pré e o pós teste, enquanto o rendimento global da turma 02 teve uma queda de aproximadamente $5,7 \%$. Essa diferença é muito significativa se considerarmos que se tratam de estudantes da mesma escola, mesma faixa etária e que participaram da mesma atividade. Esse fato reforça a necessidade de se levar adiante a pesquisa para dirimir as questões e hipóteses levantadas anteriormente sobre as características e perfil de cada turma.

Como já mencionado, o principal objetivo da realização da atividade experimental com as turmas de 3 o ano era fomentar a discussão sobre os aspectos conceituais e históricos inerentes ao nascimento 
da Física moderna, em particular o problema da radiação de corpo negro. Dessa forma, foi proposta aos estudantes, como instrumento de avaliação, a elaboração de um texto dissertativo que deveria conter no mínimo quatro palavras-chave, dentre seis elencadas: experimento, corpo negro, revolução científica, Física Quântica, radiação e temperatura.

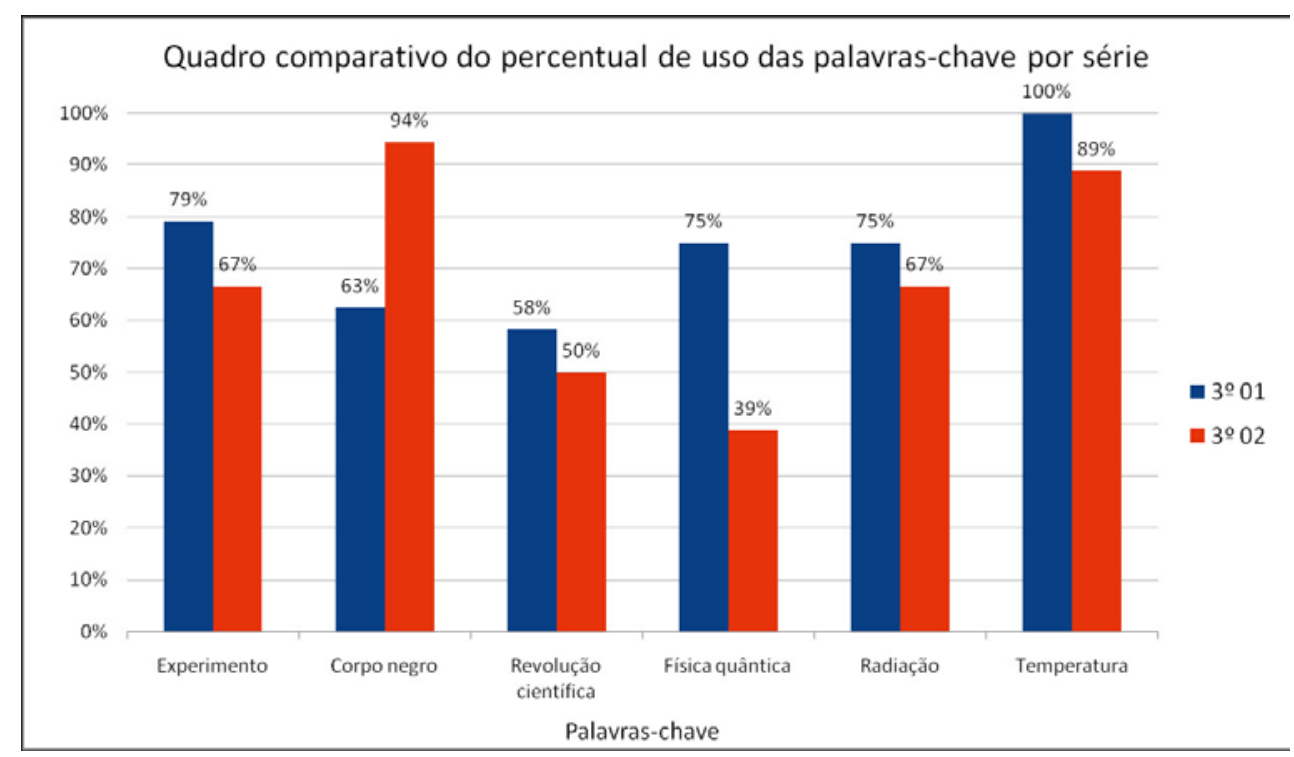

Figura 6: Distribuição percentual do uso das palavras-chave nas turmas 3으 01 e 3o 02 . Fonte: Dados desta pesquisa.

0 gráfico da figura 6 mostra um quadro comparativo da distribuição de frequência de uso das palavraschave por turma. Os números e a coerência observada dos textos produzidos evidenciaram que a atividade foi exitosa em ambas as turmas, mas se percebe que, com exceção de "corpo negro", todas as palavras apareceram com maior frequência nos textos da turma 3 응. 01 . Este resultado somado à análise qualitativa dos textos elaborados demonstra maior êxito da atividade nesta turma.

A palavra "temperatura" teve maior incidência, o que já era de certa forma esperado, por ser o elemento central da atividade, seguida da expressão "corpo negro". Esta constatação, somada à coerência com a qual as palavras foram empregadas nos textos, permite a conclusão de que o objetivo de discutir o surgimento da Física Quântica a partir do problema da radiação de corpo negro foi alcançado.

Além das atividades acima, durante a execução do projeto, buscaram-se evidências do impacto das ações desenvolvidas na formação dos estudantes bolsistas. Para tal propósito, solicitou-se a elaboração de um relatório das atividades desenvolvidas, que contemplasse aspectos relacionados a experiência, percepção, dificuldades e aprendizagem durante a realização do projeto de extensão.

Os resultados obtidos apresentaram poucos elementos críticos, uma vez que os relatos tiveram um caráter mais descritivo do que avaliativo-reflexivo. Apesar disso, a partir do acompanhamento e observação da desenvoltura e postura dos estudantes durante a execução das atividades, foi constatado comprometimento, engajamento e compreensão dos elementos teóricos e pedagógicos necessários para o bom desenvolvimento do projeto. Além desses elementos, é importante destacar que as atitudes dos bolsistas revelaram indícios do aprimoramento de capacidades relevantes para o mundo do trabalho, tais como: liderança, relação interpessoal, profissionalismo e postura ética. Além disso, esta foi a primeira experiência de iniciação científica desses estudantes, contribuindo para a promoção da autoestima destes na condição de ingressantes na instituição.

\section{CONSIDERAÇÕES FINAIS}

Além das considerações já feitas a partir dos resultados da aplicação da proposta, cabe ressaltar o potencial que as atividades experimentais possuem de, quando precedidas de um bom planejamento, suscitar e ampliar possibilidades de abordagens no ensino de Física. Além disso, o uso de enfoques distintos a partir de um mesmo aparato experimental possibilita ao professor discutir importantes aspectos da ciência e constitui-se num importante recurso metodológico, pois otimiza a gestão do tempo e dos recursos necessários para a realização da atividade e amplia o número de estudantes envolvidos na mesma. Enfim, 
a variação no enfoque dado à atividade experimental no contexto da aplicação da proposta mostrou-se uma atividade enriquecedora não apenas para os estudantes, mas também para os professores e bolsistas extensionistas.

Com isso, concluímos que os objetivos deste projeto de extensão foram alcançados na medida em que, a partir da mesma atividade experimental, cujo objetivo era estimar a temperatura da superfície do Sol, ampliamos o escopo da atividade abrangendo objetivos de caráter mais formativos como a abordagem dos aspectos da natureza da ciência, nas turmas do 10 ano; a discussão dos conceitos de temperatura, calor e energia interna, nas do 2 o ano e; por último, a discussão de aspectos conceituais e históricos inerentes ao nascimento da física moderna, no 3o ano.

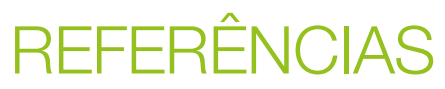

ARAUJO, Mauro Sérgio Teixeira de; ABIB, Maria Lúcia Vital dos Santos. Atividades experimentais no ensino de física: diferentes enfoques, diferentes finalidades. Revista Brasileira de Ensino de Física, São Paulo, v. 25, n. 2, p. 176-194, jun. 2003. Disponível em: http://www.scielo.br/scielo.php?script=sci_arttext\&pid=S1806$11172003000200007 \&$ Ing=en\&nrm=iso. Acesso em: 04 dez. 2018.

BRASIL. Ministério da Educação. Secretaria de Educação Média e Tecnológica. PCN+: Orientações Educacionais Complementares aos Parâmetros Curriculares Nacionais (PCNs). Brasília: MEC/SEMTEC, 2002.

CHEN, Sufen. Development of an instrument to assess views on nature of science and attitudes toward teaching science. Science Education, v. 90, n. 5, p. 803-819, 2006. Disponível em: https://onlinelibrary.wiley. com/doi/abs/10.1002/sce.20147. Acesso em: 23 fev. 2018.

GRIEBELER, Adriane; MOREIRA, Marco Antonio. Tópicos de física quântica para o ensino médio a partir de uma unidade de ensino potencialmente significativa. Textos de Apoio Ao Professor de Física, Porto Alegre, v. 23, n. 6, p. 1-39, 2012. Disponível em: http://www.if.ufrgs.br/public/tapf/v23_n6_griebeler_moreira.pdf. Acesso em: 27 nov. 2018.

LANG DA SILVEIRA, Fernando; MOREIRA, Marco Antônio. Validación de um test para verificar si el alumno posee concepciones científicas sobre calor, temperatura y energía interna. Enseñanza de las Ciencias, Barcelona, $v$. 14, n. 1, p. 75-86, 1996.

MORTIMER, Eduardo Fleury. Conceptual change or conceptual profile change? Science \& Education, v. 4, n. 3, p. 265-287, 1995.

MOURA, Breno Arsioli. 0 que é natureza da Ciência e qual sua relação com a História e Filosofia da Ciência? Revista Brasileira de História da Ciência, Rio de Janeiro, v. 7, n. 1, p. 32-46, jun. 2014. Disponível em: http:// www.sbhc.org.br/arquivo/download?ID_ARQUIVO=1932. Acesso em: 26 fev. 2018.

RODRIGUES, Renato da Silva Rosa. Formação e Evolução Estelar como uma Proposta para o Ensino de Termodinâmica no Ensino Médio. 2016. 106 f. Dissertação (Mestrado) - Curso de Programa de Pós-graduação em Física, Universidade Federal de Santa Catarina, Florianópolis, 2016. Disponível em: http://tede.ufsc.br/ teses/PPEF-F0002-D.pdf. Acesso em: 08 fev. 2018.

SASSERON, Lúcia Helena. Alfabetização científica, ensino por investigação e argumentação: relações entre ciências da natureza e escola. Revista Ensaio, Belo Horizonte, v. 17, n. especial, p. 49-67, nov. 2015. Disponível em: www.scielo.br/pdf/epec/v17nspe/1983-2117-epec-17-0s-00049.pdf. Acesso em: 17 jan. 2018.

SILVA, Osmar Henrique Moura da; LABURÚ, Carlos Eduardo; NARDI, Roberto. Reflexões para subsidiar discussões sobre o conceito de calor na sala de aula. Caderno Brasileiro de Ensino de Física, Florianópolis, v. 25, n. 3 , p. 383-396, dez. 2008. Disponível em: https://periodicos.ufsc.br/index.php/fisica/article/download/21757941.2008v25n3p383/8458. Acesso em: 14 mar. 2018.

SOARES NETO, Joaquim José; KARINO, Camila Akemi; JESUS, Girlene Ribeiro de; ANDRADE, Dalton Francisco de. A infraestrutura das escolas públicas brasileiras de pequeno porte. Revista do Serviço Público, Brasília, v. 64, n. 3, p. 377-391, jul./set. 2013. 